\title{
Reasons for consuming in a workplace canteen, factors affecting meal choice, and the perceived value of additional information on workplace canteen meals
}

\author{
S. Price ${ }^{1}$, K.M. Appleton ${ }^{1}$, J. Bray ${ }^{1}$, A. Giboreau ${ }^{2}$, F.J.A. Perez-Cueto ${ }^{3}$, I. Mavridis ${ }^{4}$, M. Ronge ${ }^{5}$ \\ and H. Hartwell ${ }^{1}$ \\ ${ }^{1}$ Bournemouth University, Poole, UK, ${ }^{2}$ Institut Paul Bocuse, Ecully, France, ${ }^{3}$ University of Copenhagen, Copenhagen, \\ Denmark, ${ }^{4}$ University of Macedonia, Thessalonika, Greece and ${ }^{5}$ Ronge \& Partners, Baden, Austria
}

Compared to meals prepared at home, meals eaten out typically contain more energy and more fat ${ }^{(1)}$. Meal selection is known to be influenced by situation ${ }^{(2)}$ and information available ${ }^{(3)}$, but little work currently investigates meal selection in a workplace canteen. This study aimed to explore the decision to eat in a workplace canteen, choice of meal in this situation, and the perceived value of additional information.

Due to the exploratory nature of the study, factors were elucidated using focus groups. Eight focus groups, involving 40 (29 female, 11 male) regular workplace canteen users were run in Denmark, France, Greece and the UK (two groups per country). To ensure consistency a structured question guide was used, focusing on reasons for consuming in a workplace canteen, factors affecting meal choice, and the perceived value of additional information. Focus groups were transcribed verbatim, and analysed using thematic analysis.

Four themes were identified in relation to the decision to eat or not eat in the work place canteen. Two themes - 'taking a break' and 'convenience' were typically given as reasons to eat in the canteen, while two themes - 'low expectations' and 'food scandals' were associated more with decisions not to eat in the canteen, not to eat certain foods/dishes, or to eat only familiar, tried and tested 'safe' foods/dishes. Once individuals decided to eat in the canteen, eleven themes related to meal choice. These themes were labelled 'value for money', 'variety', 'naturalness', 'nutrition', 'portion size', 'taste and visual appearance', 'origin', 'animal welfare', 'environmental impact', 'fair trade' and 'organic', and influenced both the consumption and the non-consumption of dishes. In relation to increased information, identified themes were 'consumers' right to information', 'aid to decision-making', 'difficulty, inconvenience and overload of information', 'information on ingredients', and 'information on nutrition'. Increased information, assuming that of relevance to the individual, was largely welcomed.

These findings suggest that consumers choose to eat in their workplace canteen and choose specific meals for a variety of reasons. In addition, consumers expressed an interest in the option of increased information on workplace canteen meals, provided this information was relevant to them. These findings suggest the need for increased information provision on workplace canteen meals, but that consumers would prefer to personalise the information they receive. Personalised information has previously been demonstrated as more influential that generic information for dietary and health outcomes ${ }^{(4)}$. These findings suggest the value of an interactive platform for information provision. The aim of the Marie Curie EU-funded project FoodSMART is to develop a mobile phone application to enable this interactive personalised information provision.

1. Lachat C, Nago E, Verstraeten R, et al. Eating out of home and its association with dietary intake: a systematic review of the evidence. Obes Rev. 2012, 13, 329-346.

2. Machín L, Giménez A, Vidal L, Ares G. Influence of context on motives underlying food choice. Journal of Sensory Studies, 2014, 29, 313-324.

3. Vanderlee L, Hammond D. Does nutrition information on menus impact food choice? Comparisons across two hospital cafeterias. Public Health Nutr. 2014, 17, 1393-1402.

4. Brinberg D, Axelson ML, Price S. Changing food knowledge, food choice, and dietary fiber consumption by using tailored messages. Appetite. $2000,35,35-43$. 